\title{
High-Performance Polymeric Surfactant of Sodium Lignosulfonate-Polyethylene Glycol 4000 (SLS-PEG) for Enhanced Oil Recovery (EOR) Process
}

\author{
Slamet Priyanto1, Ronny Windu Sudrajat', Suherman Suherman ${ }^{1 *}$, Bambang Pramudono1, \\ Teguh Riyanto', Teodora M. F. B. Dasilva', Rima Chairani Yuniar', Hanifa Aviana'

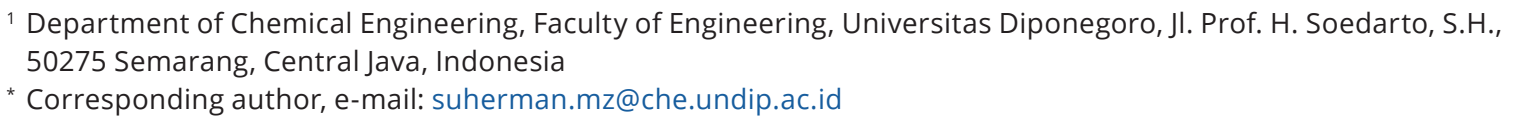

Received: 02 February 2021, Accepted: 20 May 2021, Published online: 05 October 2021

\begin{abstract}
Recently, the increase in fuel oil demand was not supported by petroleum production due to the low productivity of old wells. Furthermore, an appropriate technology, such as Enhanced Oil Recovery (EOR) technology, is needed to maximize the productivity of the old well. Therefore, the purpose of this study was to synthesize a polymeric surfactant for the EOR process from sodium lignosulfonate (SLS) and polyethylene glycol (PEG) in various SLS to PEG ratios, namely 1:1 (PS1), 1:0.8 (PS2), and 1:0.5 (PS3). The surfactants were characterized using several methods, such as Fourier Transform-Infrared spectroscopy (FT-IR), compatibility, stability, viscosity, and phase behavior tests. The performance of the surfactants for the EOR process in different brine solution concentrations $(16,000 \mathrm{ppm}$ and 20,000 ppm) was also studied. The result showed that the introduction of the PEG molecule to the surfactant had been successfully conducted as FT-IR analysis confirmed. The surfactant's hydrophilicity increased with the introduction of PEG due to the increase of the ether group. A Winsor Type I or lower phase microemulsion was formed due to the high hydrophilicity. The highest oil yield (79 \%) was obtained by PS1 surfactant, which has the highest PEG dosage, in a brine solution of 1,600 ppm. Therefore, it was concluded that the introduction of PEG could increase the hydrophilicity, viscosity, and EOR performance.
\end{abstract}

Keywords

sodium lignosulfonate, polyethylene glycol, surfactant, polymeric surfactant, enhanced oil recovery, core flooding

\section{Introduction}

In this decade, the world industry, especially in Indonesia, has been increasing; consequently, the energy demand will also increase. The main energy source for Indonesia and the world comes from petroleum so that petroleum reserves are decreasing. One of the efforts that can be done to overcome this problem is by optimizing old wells through tertiary recovery. The Enhanced Oil Recovery (EOR) method is one of the methods that can be used. EOR is a technique to increase oil recovery from fields that are already producing using primary production methods. Several types of EOR methods are commonly used, namely thermal EOR or TEOR, chemical EOR or CEOR, gas flooding miscible and immiscible EOR or GEOR, and microbial EOR or MEOR processes [1]. One of the low-cost and most developed EOR methods is chemical injection or CEOR process [1]. The chemical that can be injected is surfactant or polymer material to change the properties of fluid or oil; therefore, it makes the oil is easier to flow onto the surface [2]. However, the chemical can be adsorbed by the surface of the rock during the surfactant flooding process [3]. Therefore, it is important to develop a surfactant that has a low tendency to be adsorbed by the surface of the rock.

Surfactants can be anionic, cationic, and nonionic. The anionic surfactant is relatively stable, so that it is widely used for EOR process purposes. On the other hand, it has a low tendency to be adsorbed by the rocks in the reservoir, unlike cationic surfactant [4]. The nonionic surfactant is widely used to improve the surfactant properties as the co-surfactant. Nonionic surfactant has no anionic head; however, the ether group can form hydrogen bonding with water that can improve the hydrophilicity $[5,6]$. On the other hand, it also has a high resistance to high salinity [4]. For EOR purposes, the surfactant is used to reduce the interfacial tension between oil and brine [1]; therefore, 
the microemulsion can be formed. The microemulsions formed can be classified through the Winsor type microemulsions classification. The Winsor type microemulsion classification is depicted in Fig. 1 [7]. According to Zulkifli et al. [8], the best microemulsion type for EOR process purposes is Winsor Type III, followed by Winsor Type I, and the last is Winsor Type II. However, Winsor Type I microemulsion can be changed to Winsor Type III microemulsion by changing several parameters, such as the concentration of surfactant, salinity of the brine used, and so on [8]. Polymeric surfactant is very attractive to the EOR method. Polymers are used to increase the viscosity and simultaneously, surfactants can reduce interface stress or emulsifiers [9].

One of the ingredients for the polymeric surfactant that has started to be developed at this time is lignin. This is based on the fact that lignin is the main part of plant cell walls so that the amount of this compound is very abundant and is the second-largest and renewable resource on earth after cellulose [10]. Babu et al. [11] studied the synthesis of surfactants-PMES polymers (polymeric ester sulfonate) with SMEs surfactants (sodium methyl ester sulfonate). The results showed that the SMEs and PMES polymers could reduce face stress by $10^{-2}-10^{-3} \mathrm{mN} / \mathrm{m}$ [11]. Therefore, this polymer can be used in the EOR process. Yin and Zhao [12] studied the effect of viscosity and face stress for oil uptake in heterogeneous reservoirs and determined controlling factors on surfactant-polymer (SP) flooding. The results showed that the higher the polymer concentration would increase the viscosity. However, if the concentration of the polymer and the viscosity are too high, it may block the reservoir; contrarily, if the concentration of the polymer and the viscosity are too low, the mobility is not appropriate [13].

The attractive lignin-based surfactant for the EOR process is sodium lignosulfonate (SLS) [14-17]. The SLS

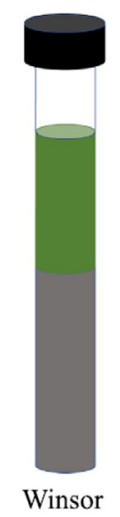

Type I

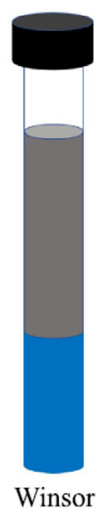

Type II
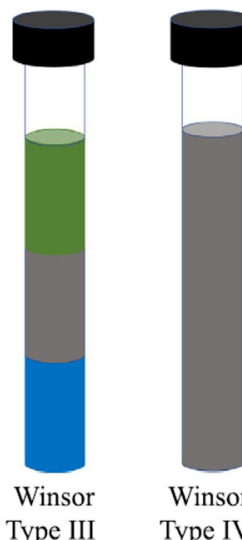

molecule consists of the aromatic skeleton as the hydrophobic and sulfonic groups as the hydrophilic group [18]. The molecular structure of SLS is depicted in Fig. 2(a). Teng et al. [19] reported that SLS has a water-soluble characteristic. However, sulfonate-type surfactants precipitate in the brine solution in which divalent ions are present because they are sensitive to divalent ions [8]. On the other hand, polyethylene glycol (PEG) is a polymer that has high hydrophilicity [6]. The molecular structure of PEG is depicted in Fig. 2(b). In addition, PEG has excellent resistance to high salinity levels because of nonionic surfactant [4]. Previously, we have developed SLS-PEG polymeric surfactant for the EOR process. The PEG used was low molecular weight (PEG-400) and the brine solution was low (5,000 ppm). Therefore, this study synthesizes a high-performance polymeric surfactant and investigates the effect of PEG addition with high molecular weight (PEG-4000) to SLS surfactant on polymeric surfactant properties and performance for the EOR process. Furthermore, the effect of brine solution is also investigated. To the best of our knowledge, there is still limited study of investigating these matters. Therefore, we stand out to cover these matters.

\section{Materials and methods}

\subsection{Materials}

Sodium Lignosulfonate (SLS) with molecular weight (MW) of $534.5 \mathrm{~g} / \mathrm{mol}$ was synthesized using the lignin sulfonation method from black liquor from PT. Indah Kiat Pulp and Paper Mill in Pekanbaru, Riau, West Sumatra. Kawengan oil is obtained from STEM AKAMIGAS Cepu. The physical properties of Kawengan oil are presented in Table 1. The other materials are Polyethylene Glycol with molecular weight of 4,000 gram/mol (PEG-4000) as the polymer raw material, ammonium persulfate, acetone, and demineralized

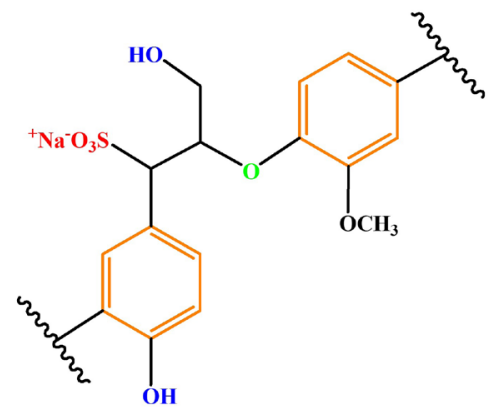

(a)

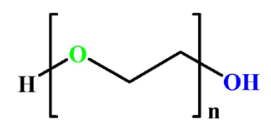

(b)
Fig. 2 Molecular structure of (a) sodium lignosulfonate (SLS) and (b) polyethylene glycol (PEG).

Fig. 1 Winsor type microemulsions [7]. 


\begin{tabular}{lc}
\multicolumn{2}{l}{ Table 1 Physical properties of Kawengan oil } \\
\hline Parameters & Value \\
\hline Viscosity, Poise $\left(30{ }^{\circ} \mathrm{C}\right)$ & 0.96 \\
Density, g/ml & 0.843 \\
Flash point, ${ }^{\circ} \mathrm{C}$ & 115 \\
Pour point, ${ }^{\circ} \mathrm{C}$ & 27 \\
\hline
\end{tabular}

water obtained from the Integrated Laboratory of Universitas Diponegoro, Semarang, Central Java.

\subsection{Synthesis of polymeric surfactant}

All experiments were performed at the Laboratory of Chemical Engineering, Department of Chemical Engineering, Faculty of Engineering, Universitas Diponegoro. Several steps were followed to synthesize the SLS, namely the isolation of lignin and the sulfonation of lignin to obtain the SLS. The synthesis was conducted following the method presented by Priyanto et al. [16]. The reaction was carried out with SLS surfactant and PEG using ammonium persulfate to synthesized the polymeric surfactant. The ratios of SLS and PEG tested were 1:1, 1:0.8, and 1:0.5 (afterward named as PS1, PS2, and PS3, respectively). SLS was dissolved in $80 \mathrm{ml}$ of demineralized water, PEG was dissolved in $10 \mathrm{ml}$ of demineralized water, and ammonium persulfate was dissolved in $10 \mathrm{ml}$ of demineralized water. The SLS and PEG solutions were put into a three-neck flask and heated at a temperature of $70{ }^{\circ} \mathrm{C}$, with a stirring speed of $300 \mathrm{rpm}$. After the temperature was reached, the ammonium persulfate solution was then put in a three-neck flask to react to the polymeric surfactant. The reaction was carried out for $2 \mathrm{~h}$. The product of this reaction was extracted using acetone and then put into the oven for $12 \mathrm{~h}$ before characterization tests.

\subsection{Characterization methods}

In this experiment, Fourier transform-Infrared (FT-IR) analysis, compatibility, thermal stability, viscosity, phase behavior, and core flooding test was carried out to determine the characteristic of the polymeric surfactant. Before carrying out the tests as mentioned above, PS1, PS2, and PS3 surfactants with $0.1 \%$ wt concentration were dissolved into brine water, with two different concentrations of 16,000 ppm and 20,000 ppm, respectively.

\subsubsection{FT-IR analysis}

This test was performed to determine the substitution groups in the polymeric surfactant. FT-IR spectra were obtained on a Perkin-Elmer Infrared spectrophotometer.
The samples were scanned in the wavenumber range of $4000-400 \mathrm{~cm}^{-1}$.

\subsubsection{Compatibility test}

The changes on the polymeric surfactant-brine solution were observed gradually. The polymeric surfactant was tested by mixing it with brine solutions. The brine solutions were varied at $16,000 \mathrm{ppm}$ and $20,000 \mathrm{ppm}$. The concentration of the surfactant is $0.1 \mathrm{wt} \%$. The solutions were observed for 21 days.

\subsubsection{Thermal stability test}

In this test, polymeric surfactant in brine solutions with $16,000 \mathrm{ppm}$ and 20,000 ppm concentrations were heated at the reservoir temperature $\left(70^{\circ} \mathrm{C}\right)$ for 21 days. The polymeric surfactant was gradually observed and the density was also measured.

\subsubsection{Viscosity test}

The viscosity of the polymeric surfactants at different SLS-PEG ratios and for different brine concentrations (16,000 ppm and 20,000 ppm) were measured using the Ostwald viscometer.

\subsubsection{Phase behavior test}

Polymeric surfactant, injection water (brine), and oil were mixed into a test tube. The volume ratio of the injection water (containing $0.1 \mathrm{wt} \%$ surfactants) to oil was 1:1. The mixture was shaken and then heated in an oven until it reached a reservoir temperature $\left(70^{\circ} \mathrm{C}\right)$ for 21 days.

\subsubsection{Core flooding test}

This test was performed according to the method presented by Priyanto et al. [20] and Sudrajat et al. [17]. This test was conducted using a core flooding unit to determine the oil yield. The core flooding unit has been designed in such a way as to illustrate the core rocks during the actual oil recovery.

\section{Results}

3.1 Synthesized polymeric surfactant and FT-IR analysis The polymeric surfactant from SLS and polyethylene glycol (PEG) was synthesized following the previously reported studies [11,17]. The synthesized polymeric surfactants are analyzed using FT-IR to determine the functional groups present in the surfactants. The FT-IR spectra were recorded at a wavenumber of $4000-400 \mathrm{~cm}^{-1}$. The infrared spectra of the surfactants are presented in Fig. 3. 


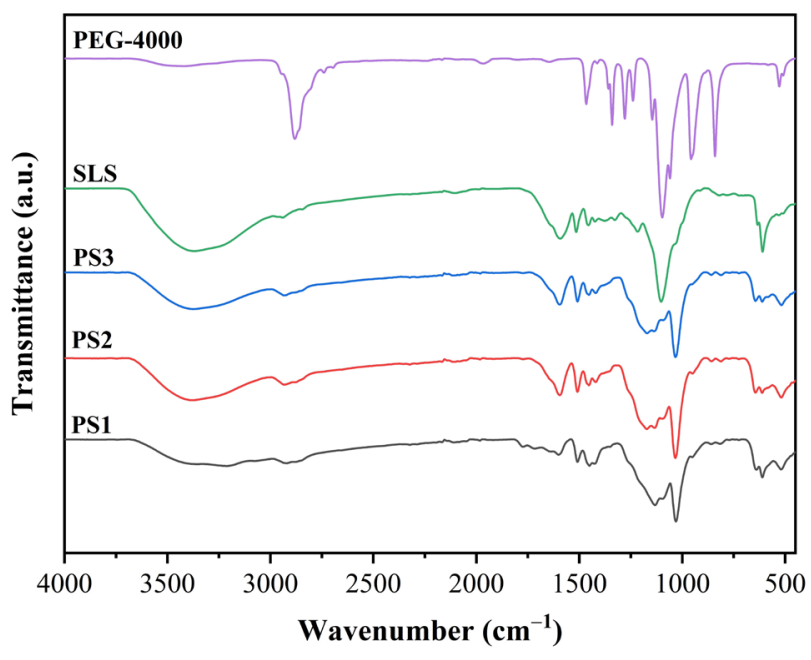

Fig. 3 Infrared spectra of polymeric surfactants.

The FT-IR spectra of the surfactants are deconvoluted using the Gaussian equation to investigate the peak present in the surfactants. The deconvoluted spectra are presented in Fig. 4. The broad intensity between $3600-3200 \mathrm{~cm}^{-1}$ is attributed to the hydroxy group stretch [21]. As can be seen, there are three bands in this range, namely $\sim 3550 \mathrm{~cm}^{-1}$, $\sim 3400 \mathrm{~cm}^{-1}$, and $\sim 3200 \mathrm{~cm}^{-1}$. These peaks are attributed to the vibration of $\omega_{\gamma} \mathrm{O}-\mathrm{H}, \omega_{\delta} \mathrm{O}-\mathrm{H}$, and $\omega_{\varepsilon} \mathrm{O}-\mathrm{H}$ [22]. On the other hand, Kubo and Kadla [23] reported that these three peaks correspond to the intramolecular $\left(\sim 3550 \mathrm{~cm}^{-1}\right)$ and intermolecular $\left(\sim 3400\right.$ and $\left.\sim 3200 \mathrm{~cm}^{-1}\right)$ hydrogen bond of $\mathrm{O}-\mathrm{H}$. The $\mathrm{O}-\mathrm{H}$ stretch for normal polymer appears at $\sim 3400 \mathrm{~cm}^{-1}[21,24]$. This peak is associated with the PEG molecule. The band at $3045-3037 \mathrm{~cm}^{-1}$ corresponds to the vibration of aromatic $\mathrm{C}-\mathrm{H}$. The appearance of this peak indicates that the polymeric surfactants contain an aromatic structure. It is true since the associated peak appears at $\sim 1590 \mathrm{~cm}^{-1}$, which represents the $\mathrm{C}=\mathrm{C}$ vibration of an aromatic ring. The aromatic structure is detected from SLS molecules. The peaks at $\sim 2936$ and $\sim 2850 \mathrm{~cm}^{-1}$ correspond to the $\mathrm{C}-\mathrm{H}$ stretching vibration of methyl $\left(-\mathrm{CH}_{3}\right)$ and methylene $\left(-\mathrm{CH}_{2}-\right)$ aliphatic groups $[19,25]$. This methylene group comes from PEG molecules.

The peak at $\sim 1640 \mathrm{~cm}^{-1}$ corresponds to the $\mathrm{O}-\mathrm{H}$ scissoring. As mentioned, the peak at $\sim 1590 \mathrm{~cm}^{-1}$ is attributed to the aromatic ring $(\mathrm{C}=\mathrm{C}$ vibration), which is associated with the peak at $\sim 1508 \mathrm{~cm}^{-1}$. The sulfonate group is pointed out by the peaks at $\sim 1640 \mathrm{~cm}^{-1}$ [21], and followed by the associated peaks at $\sim 1200 \mathrm{~cm}^{-1}$ (ascribed as $\mathrm{S}=\mathrm{O}$ band), $\sim 1130 \mathrm{~cm}^{-1}$ (asymmetric stretch vibration of $\mathrm{S}=\mathrm{O}$ ) [15], 1030 $\mathrm{cm}^{-1}$ (C-S band), and $\sim 640 \mathrm{~cm}^{-1}$ (S-O band) [26]. Peaks at $\sim 1169 \mathrm{~cm}^{-1}, \sim 1080 \mathrm{~cm}^{-1}$, and $\sim 1014 \mathrm{~cm}^{-1}$ are attributed to the asymmetric vibration of the $\mathrm{C}-\mathrm{O}-\mathrm{C}$ bridge, $\mathrm{C}-\mathrm{O}$ deformation, and $\mathrm{C}-\mathrm{O}-\mathrm{C}$ stretch vibration, respectively.
The peaks at $\sim 3400 \mathrm{~cm}^{-1}, \sim 2850 \mathrm{~cm}^{-1}$, and $\sim 1169 \mathrm{~cm}^{-1}$ are attributed to the $\mathrm{O}-\mathrm{H}, \mathrm{C}-\mathrm{H}$, and $\mathrm{C}-\mathrm{O}-\mathrm{C}$ of the $\mathrm{PEG}$ structure. On the other hand, the peak at $\sim 1590 \mathrm{~cm}^{-1}$ is attributed to the $\mathrm{C}=\mathrm{C}$ vibration of the aromatic ring representing the SLS molecule. Therefore, the ratio of the deconvoluted area of those peaks can be used to predict PEG composition in the surfactants. Table 2 shows the ratio of $\mathrm{O}-\mathrm{H}, \mathrm{C}-\mathrm{H}, \mathrm{C}-\mathrm{O}-\mathrm{C}$, and $\mathrm{C}=\mathrm{C}$ groups. As can be seen, quantitively, the $\mathrm{PEG}$ molecule is introduced to the polymeric surfactants since the ratio of those peaks increases with the increase of PEG weight.

\subsection{Compatibility test}

The compatibility test is important to be performed to observe the compatibility of surfactant and brine solution in the reservoir. It is expected that the mixture of surfactant and brine solution is a perfect solution of colloid. The polymeric surfactant was tested by mixing it with brine solutions. The brine solutions are varied at $16,000 \mathrm{ppm}$ and 20,000 ppm. The concentration of the surfactant is $0.1 \mathrm{wt} \%$. The result of this analysis is depicted in Fig. 5. As can be seen, the polymeric surfactants are completely dissolved in the brine solutions. No precipitate is formed at the compatibility test for 21 days indicating that the suspension is not formed for all polymeric surfactants. The suspension is not allowed because it can cause clogging when it is injected for the EOR process [27, 28]. Therefore, a high soluble surfactant is desired. These facts indicate that the synthesized polymeric surfactants pass the compatibility test and applicable for the EOR process.

The high solubility of this polymeric surfactant is due to the presence of ether groups on PEG. The ether group could bind with the water molecules so that the surfactant can easily dissolve [29]. Nakama reported that the ether oxygen of the polyoxyethylene group could catch the water molecules through hydrogen bonding [29]. Based on this understanding, the possible interaction of ether groups on PEG with water molecules is depicted in Fig. 6. In this interaction, water molecules bonded to the ether oxygen of PEG separates as the temperature increases due to the dehydration process. As the temperature increases, the ether-bonded oxygen atoms and the hydrogen-bonded water molecules start to separate. This process could decrease the surfactant solubility against water due to the decrease in the hydrophilic property, causing liquid cloud formation due to the liquid-liquid detachment [29]. When the surfactant reaches its cloud point, it can no longer dissolve in water. However, the nonionic surfactants have a high cloud point as well as a high hydrophilic property. 
$118 \mid \begin{aligned} & \text { Priyanto et al. } \\ & \text { Period. Polytec }\end{aligned}$

Period. Polytech. Chem. Eng., 66(1), pp. 114-124, 2022
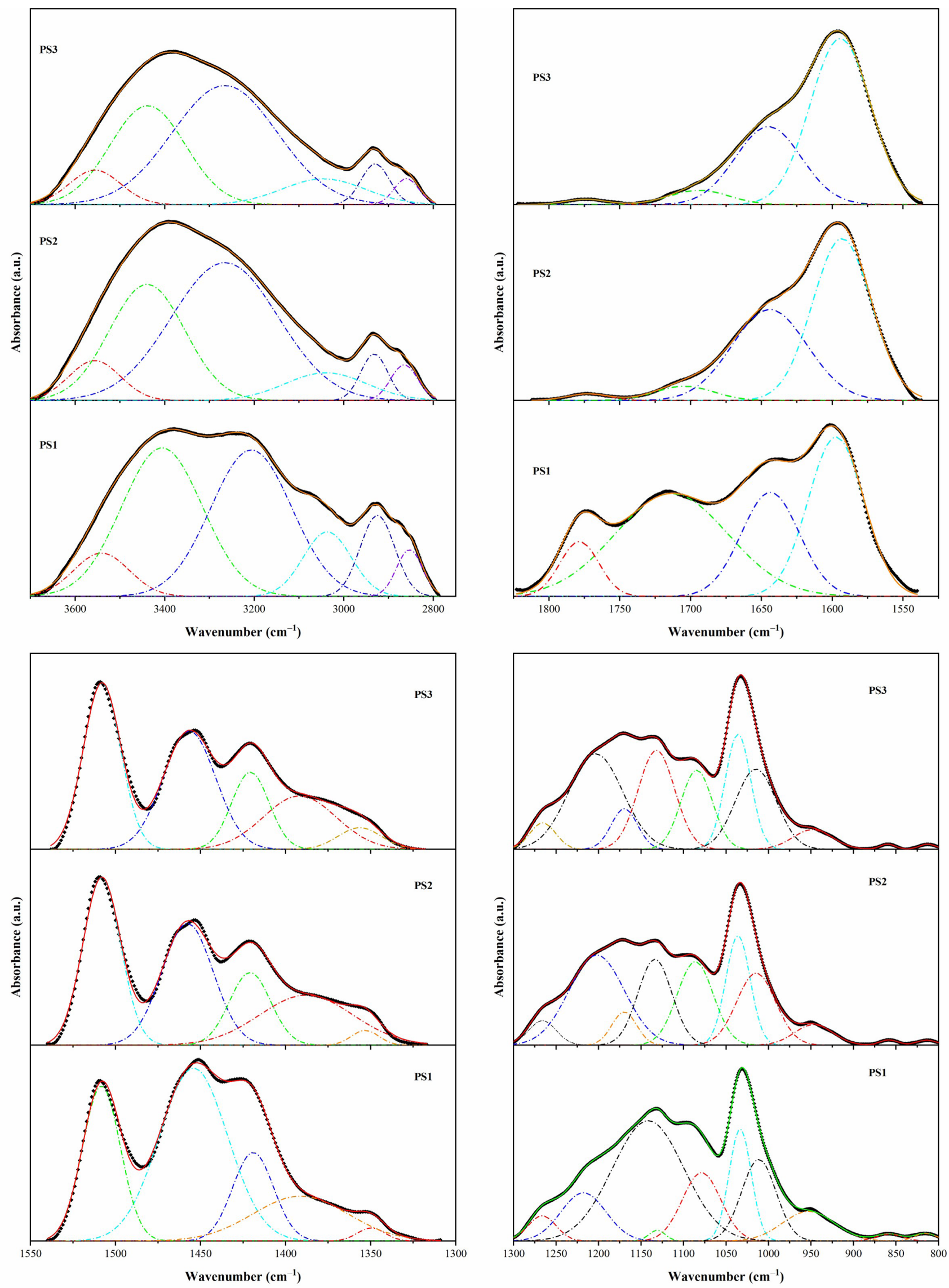

Fig. 4 Deconvoluted spectra of FT-IR analysis. 
Table 2 The deconvoluted area ratio of $\mathrm{O}-\mathrm{H}$,

\begin{tabular}{lccc}
\multicolumn{4}{c}{$\mathrm{C}-\mathrm{H}, \mathrm{C}-\mathrm{O}-\mathrm{C}$, and $\mathrm{C}=\mathrm{C}$ groups } \\
\hline Ratio & $\mathrm{PS} 1$ & $\mathrm{PS} 2$ & $\mathrm{PS} 3$ \\
\hline$A_{\mathrm{O}-\mathrm{H}} / A_{\mathrm{C}=\mathrm{C}}$ & 1.368 & 1.111 & 1.117 \\
$A_{\mathrm{C}-\mathrm{H}} / A_{\mathrm{C}=\mathrm{C}}$ & 1.289 & 0.726 & 0.685 \\
$A_{\mathrm{C}-\mathrm{O}-\mathrm{C}} / A_{\mathrm{C}=\mathrm{C}}$ & 2.867 & 1.528 & 1.414 \\
\hline
\end{tabular}
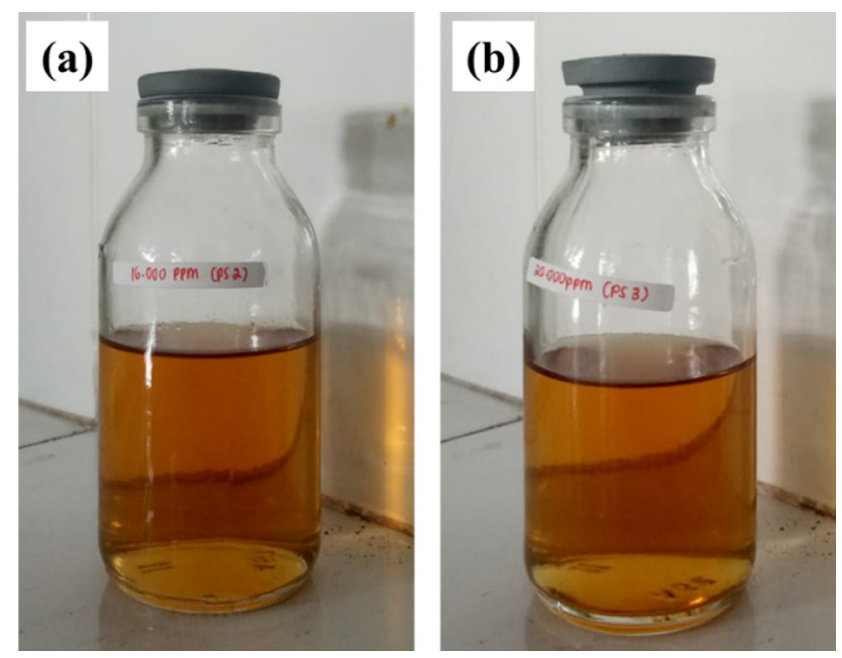

Fig. 5 The results of the polymeric surfactant solubility test for 21 days in brine solutions: (a) 16,000 ppm and (b) 20,000 ppm.

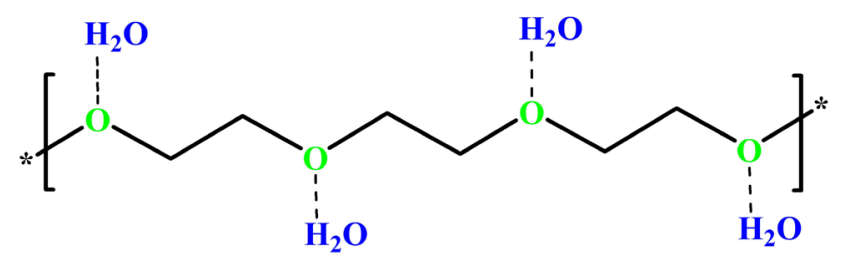

Fig. 6 Interaction of ether groups in PEG with water molecules.

Therefore, the surfactant has high solubility and high stability in the brine solution.

On the other hand, the high solubility of the surfactant is due to the presence of SLS because it is also a high soluble surfactant. Teng et al. [19] reported that SLS has a water-soluble characteristic. The molecular structure of SLS surfactant has a short chain; therefore, it can easily react with the brine resulting in good solubility [4]. On the other hand, Lim et al. [28] reported that SLS is a water-soluble anionic surfactant due to the presence of negative charges on the hydrophilic part. The negative charge comes from the sulfonate $\left(-\mathrm{SO}_{3}^{-}\right)$[28-30] and its salt $\left(\mathrm{NaSO}_{3}\right)$ [14] as the hydrophilic groups. However, sulfonate-type surfactants precipitate in the brine solution in which divalent ions are present because they are sensitive to divalent ions [8].

\subsection{Thermal stability test}

The thermal stability test is intended to determine the effect of heat on surfactant performance. The tests in this study were carried out by observing the changes in the solution at $70{ }^{\circ} \mathrm{C}$ for 21 days. The advisable surfactant is the surfactant that does not produce precipitate due to the heating process. The thermal stability test is conducted by observing the change of the density of surfactant dissolved in the brine solution. As can be seen in Fig. 7, the surfactant density dissolved in brine solution of 20,000 ppm is higher than 16,000 ppm. This finding is in accordance with some previous studies reported. Yanti et al. [31] reported that the density of surfactant-brine solution increased with the increase in salinity levels.

As shown in Fig. 7, the synthesized polymeric surfactants from SLS and PEG are relatively stable. The density of the surfactants in the brine solutions is relatively constant. This fact confirms that the surfactants are stable at reservoir temperature $\left(70^{\circ} \mathrm{C}\right)$. In addition, the density that tends to be stable indicates that there are no changes in molecular weight, which can be caused by the degradation by heat. On the other hand, on 21 days of aging, the surfactants are not precipitated (Fig. 7(b)). It indicates that the synthesized polymeric surfactants are highly stable to form the solution. This fact is in accordance with the compatibility test result. The surfactants are highly soluble due to the presence of ether-bonded oxygen atoms from the PEG molecule [29]. In addition, the high stability of the surfactants, even at high salinity levels, is due to the presence of PEG as the polymer and nonionic species. As Sudarmoyo et al. [4] reported, the nonionic surfactant has more excellent resistance to high salinity levels. This property has a high impact on surfactant stability. Furthermore, these facts confirm that the surfactant is thermally stable at the reservoir temperature $\left(70{ }^{\circ} \mathrm{C}\right)$ and applicable for the EOR process.

\subsection{Surfactants viscosity test}

Surfactant viscosity is an important parameter in the EOR process. However, the rock may be blocked if the surfactant viscosity is too high. On the other hand, the mobility reduction is inadequate if the surfactant viscosity is too low [13]. Therefore, the viscosity of the surfactant has to be optimized. However, it is reported that high viscosity surfactant is required to reduce the oil-water mobility ratio and enhance oil recovery [12]. Fig. 8 shows the viscosity of the polymeric surfactants. 


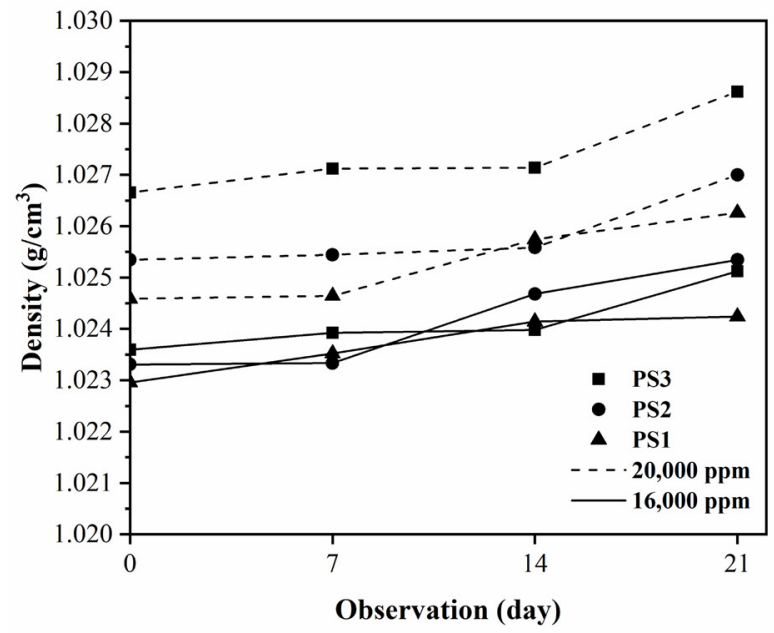

(a)

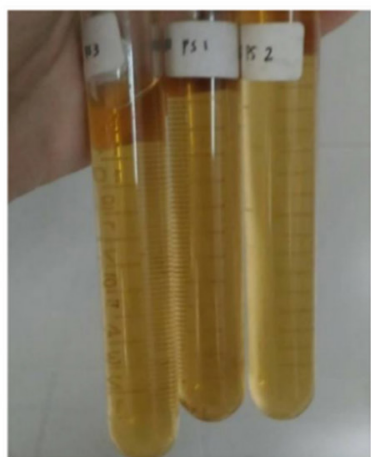

(b)

Fig. 7 Stability test for 21 days at $70^{\circ} \mathrm{C}$ : (a) density of surfactant solutions and (b) surfactant solutions appearance on day 21 .

As shown in Fig. 8, the viscosities of PS1, PS2, and PS3 surfactants in $16,000 \mathrm{ppm}$ brine solution are $0.9153,0.8755$, and 0.8735 centipoises, respectively. On the other hand, the viscosities of PS1, PS2, and PS3 surfactants in 20,000 ppm brine solution are $0.9393,0.9264$, and 0.866 centipoises, respectively. Based on those data, the polymeric surfactant's viscosity is affected by the polymer concentration (ratio of SLS surfactant to PEG polymer). The polymeric surfactants' viscosity increases with the increase in polymer concentration. This finding is in line with the previously reported study by Sudrajat et al. [17]. The amount of PEG added to the SLS-based surfactants affects its viscosity. They reported that the viscosity of surfactant increased with the increase in PEG amount. It is true since PEG is a

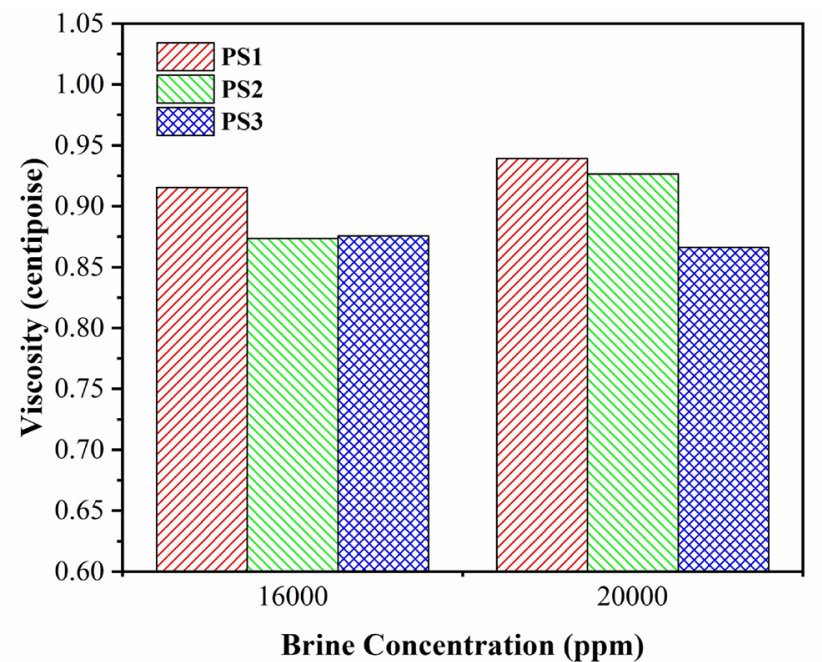

Fig. 8 The viscosity of surfactants at different brine solutions. polymer that can be added to increase the viscosity of the injecting brine for the EOR process [32, 33].

On the other hand, as shown in Fig. 8, the viscosity of the polymeric surfactants is different at different brine solution concentrations. The viscosity of the SLS-PEG polymeric surfactant in the brine solution concentration of $16,000 \mathrm{ppm}$ is lower than the viscosity in the brine solution concentration of $20,000 \mathrm{ppm}$. It confirms that the viscosity of the polymeric surfactant increases as the brine solution concentration increase. This finding is in line with some previous studies [31, 34].

\subsection{Phase behavior test}

The objective of this test is to investigate the microemulsion formation of the polymeric surfactants. The mixed fluid for phase behavior test consists of oil and injection water (brine) containing $0.1 \%$ polymeric surfactants. The test was carried out using a tube test. The volume ratio of injection water and oil is 1:1. The mixture was then shaken and heated up to the reservoir temperature $\left(70{ }^{\circ} \mathrm{C}\right)$ for 21 days. Fig. 9 illustrates the result of the phase behavior test of the SLS-PEG polymeric surfactants. As shown in Fig. 9, the type of microemulsion obtained is the Windsor Type I microemulsion. According to Zulkifli et al. [8], the best microemulsion type for EOR process purposes is Winsor Type III, followed by Winsor Type I, and the last is Winsor Type II. Winsor Type I microemulsion can also be mentioned as Winsor Type II(-) or lower-phase microemulsion, which is the minimum type of microemulsion for EOR process purposes $[35,36]$. On the other hand, Winsor 
Type II microemulsion can also be mentioned as Winsor Type II $(+)$ or upper-phase microemulsion [36].

As shown in Fig. 9, all surfactants form Winsor Type I microemulsion (lower-phase microemulsion) or form oilin-water $(\mathrm{o} / \mathrm{w})$ microemulsion. This microemulsion type is formed because the surfactants used are water-based surfactants. Sudarmoyo et al. [4] stated that SLS surfactant is categorized as a water-based surfactant. It means that the hydrophilic part of SLS is stronger than the hydrophobic tail. On the other hand, the introduction of PEG molecules can increase the hydrophilicity of the surfactant. It is true since the FT-IR analysis reported that the PEG molecule had been introduced to the surfactant as the $\mathrm{C}-\mathrm{O}-\mathrm{C}$ (ether) group increases. The ether group of PEG can form hydrogen bonding with water; therefore, the PEG-based surfactant has high hydrophilicity $[5,6]$. These surfactants' properties can promote the emulsion between the brine and the oil. The surfactants will tend to pull the brine to the water zone; therefore, the brine and oil interfaces decrease [4]. On the other hand, this microemulsion formation can also be caused by the low salinity of the brine [8].

\subsection{Core flooding test}

Core flooding test requires oil samples, rock, injection water, and $0.1 \mathrm{wt} \%$ polymeric surfactant. In this study, the oil used was Kawengan oil with a density of $0.96 \mathrm{~g} / \mathrm{ml}$, which is heavy crude oil, the injection water used was a brine solution with a concentration of $16,000 \mathrm{ppm}$ and 20,000 ppm. Artificial stone (synthetic core) is designed from the closest structure to the real rock (native core). Rock compaction is carried out at both ends of the core holder until the rock is completely solid (does not break or does not fall from the core holder) with a constant pressure of 500 psi. Filters are placed at both ends of the core holder to prevent rocks from clogging the pipe from the core holder. The size of the silica sandstone is 100 mesh with a 150 -mesh filter. The core flooding tests were conducted at $70{ }^{\circ} \mathrm{C}$. The results of the core flooding tests are presented in Fig. 10.

As can be seen in Fig. 10, comparing the effect of PEG weight (PEG dosage) in the surfactant, the oil yield obtained increases as the PEG weight in the surfactant increases. At a brine concentration of 16,000 ppm, PS1 (SLS:PEG = 1:1) produces the final oil yield up to $79 \%$ with a constant time at $45 \mathrm{~min}$, PS2 (SLS:PEG = 1:0.8) produces the final oil yield up to $71 \%$ with a constant time at $40 \mathrm{~min}$, and PS3 (SLS:PEG = 1:0.5) produces the final oil yield up to $70 \%$ with a constant time at $40 \mathrm{~min}$. On the other hand, at a brine concentration of 20,000 ppm, PS1 produces the final oil yield up to $75 \%$ with a constant time at $45 \mathrm{~min}$, PS2 produces the final oil yield up to $73 \%$ with a constant time at $45 \mathrm{~min}$, and PS3 (SLS:PEG = 1:0.5) produces the final oil yield up to $71 \%$ with a constant time at $40 \mathrm{~min}$. Based on these results, it can be observed that the PS1 surfactant has the highest performance for the EOR process at both brine salinity of 16,000 ppm and 20,000 ppm. Therefore, it can be concluded that the surfactant performance on the EOR process increases as the PEG weight increases. The increase in the surfactant performance is due to the hydrophilicity properties of the surfactant. As reported in the previous section, the more the PEG introduced, the more the surfactant's hydrophilicity. This hydrophilicity is attributed to the ether $(\mathrm{C}-\mathrm{O}-\mathrm{C})$ group of the PEG molecule. This group can bond with water through hydrogen bonding [5 ,6, 29].

Concerning the effect of brine concentration on the performance of the EOR process, it can be seen that the oil yield obtained at a brine concentration of $16,000 \mathrm{ppm}$ is higher than the oil yield obtained at a brine concentration of 20,000 ppm. It confirms that at high salinity, the EOR performance is low. This finding is in line with the previous study conducted by Setiati et al. [34]. They reported that the increase in brine salinity could decrease the EOR performance.

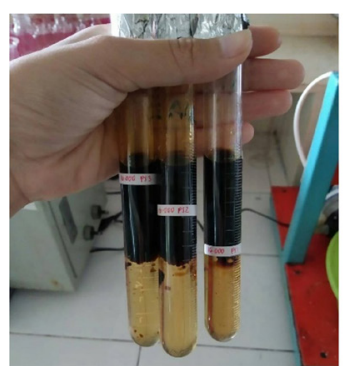

(a)

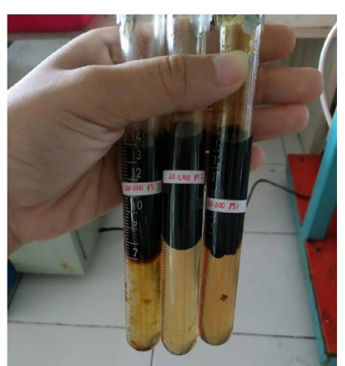

(b)

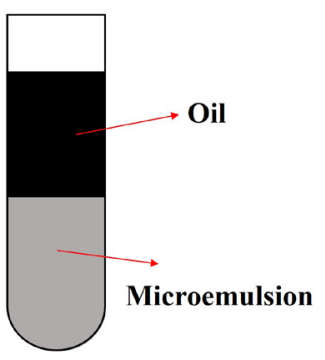

(c)

Fig. 9 The results of the 21-day phase behavior test on polymeric surfactant in a brine solution of (a) 16,000 ppm and (b) 20,000 ppm and (c) illustration of Winsor Type I microemulsion. 

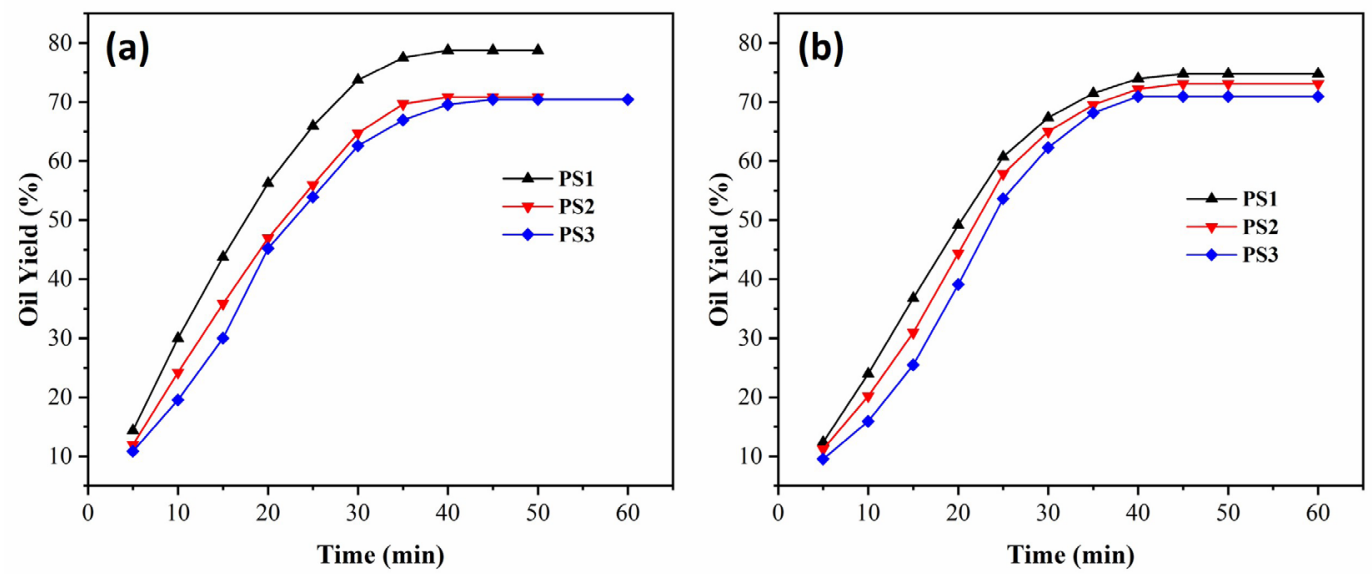

Fig. 10 EOR performance of polymeric surfactant in a brine solution of (a) 16,000 ppm and (b) 20,000 ppm.

\section{Conclusions}

In this study, a high-performance polymeric surfactant from SLS and PEG has been successfully synthesized for an EOR process of Kawengan oil (heavy crude oil). All synthesized polymeric surfactants are compatible in the brine solutions of 16,000 ppm and 20,000 ppm and thermally stable as the density value tends to be stable. It is found that the viscosity of the polymeric surfactant is affected by the concentration of the polymer added. It is also found that the microemulsion formed is a Winsor Type I microemulsion or lower phase microemulsion due to the high hydrophilicity, which is affected by the introduction of PEG. The highest oil yield,

\section{References}

[1] Nwidee, L. N., Theophilus, S., Barifcani, A., Sarmadivaleh, M., Iglauer, S. "EOR Processes, Opportunities and Technological Advancements", In: Romero-Zeron (ed.) Chemical Enhanced Oil Recovery (cEOR) - a Practical Overview, InTech, London, UK, 2016, pp. 3-52.

https://doi.org/10.5772/64828

[2] Gbadamosi, A. O., Junin, R., Manan, M. A., Agi, A., Yusuff, A. S. "An overview of chemical enhanced oil recovery: recent advances and prospects", International Nano Letters, 9(3), pp. 171-202, 2019. https://doi.org/10.1007/s40089-019-0272-8

[3] Cortés, F. B., Lozano, M., Santamaria, O., Betancur Marquez, S. B., Zapata, K., Ospina, N., Franco, C. A. "Development and Evaluation of Surfactant Nanocapsules for Chemical Enhanced Oil Recovery (EOR) Applications", Molecules, 23(7), Article number: 1523, 2018. https://doi.org/10.3390/molecules23071523

[4] Sudarmoyo, S., Swadesi, B., Andini, A. N., Siregar, S., Kurnia, R., Buhari, A., Budiaman, I. G. S. "Laboratory study: The development of a sodium lignosulfonate (SLS) surfactant formulation for light oil reservoir to improve oil recovery", AIP Conference Proceedings, 1977, Article number: 030033, 2018. https://doi.org/10.1063/1.5042953
$79 \%$, is obtained by the PS1 surfactant with the highest PEG dosage in $16,000 \mathrm{ppm}$ brine solution. The high oil yield is obtained due to the high surfactant's hydrophilicity, which is affected by the introduction of PEG.

\section{Acknowledgment}

The authors would like to express their sincere gratitude to the Ministry of Education and Culture, Indonesia, for the financial support through the research project of Penelitian Disertasi Doktor with contract number: 258-43/UN7.6.1/PP/2020.

[5] Bera, A., Mandal, A. "Microemulsions: a novel approach to enhanced oil recovery: a review", Journal of Petroleum Exploration and Production Technology, 5(3), pp. 255-268, 2015. https://doi.org/10.1007/s13202-014-0139-5

[6] Shi, Y., Shan, G., Shang, Y. "Role of Poly(ethylene glycol) in Surfactant-Free Emulsion Polymerization of Styrene and Methyl Methacrylate", Langmuir, 29(9), pp. 3024-3033, 2013. https://oi.org/10.1021/1a304847a

[7] Massarweh, O., Abushaikha, A. S. "The use of surfactants in enhanced oil recovery: A review of recent advances", Energy Reports, 6, pp. 3150-3178, 2020. https://doi.org/10.1016/j.egyr.2020.11.009

[8] Zulkifli, N. N., Mahmood, S. M., Akbari, S., Manap, A. A. A., Kechut, N. I., Elrais, K. A. "Evaluation of new surfactants for enhanced oil recovery applications in high-temperature reservoirs", Journal of Petroleum Exploration and Production Technology, 10(2), pp. 283-296, 2020. https://doi.org/10.1007/s13202-019-0713-y

[9] Raffa, P., Broekhuis, A. A., Picchioni, F. "Polymeric surfactants for enhanced oil recovery: A review", Journal of Petroleum Science and Engineering, 145, pp. 723-733, 2016. https://doi.org/10.1016/j.petrol.2016.07.007 
[10] Lin, X., Zhou, M., Wang, S., Lou, H., Yang, D., Qiu, X. "Synthesis, Structure, and Dispersion Property of a Novel Lignin-Based Polyoxyethylene Ether from Kraft Lignin and Poly(ethylene glycol)", ACS Sustainable Chemistry and Engineering, 2(7), pp. 1902-1909, 2014.

https://oi.org/10.1021/sc500241g

[11] Babu, K., Pal, N., Bera, A., Saxena, V. K., Mandal, A. "Studies on interfacial tension and contact angle of synthesized surfactant and polymeric from castor oil for enhanced oil recovery", Applied Surface Science, 353, pp. 1126-1136, 2015.

https://doi.org/10.1016/j.apsusc.2015.06.196

[12] Yin, D., Zhao, D. "Main Controlling Factor of PolymerSurfactant Flooding to Improve Recovery in Heterogeneous Reservoir", Advances in Materials Science and Engineering, 2017, Article ID: 5247305, 2017. https://doi.org/10.1155/2017/5247305

[13] Sun, C., Guo, H., Li, Y., Song, K. "Recent Advances of SurfactantPolymer (SP) Flooding Enhanced Oil Recovery Field Tests in China", Geofluids, 2020, Article ID: 8286706, 2020. https://doi.org/10.1155/2020/8286706

[14] Azis, M. M., Rachmadi, H., Wintoko, J., Yuliansyah, A. T., Hasokowati, W., Purwono, S., Rochmadi, W., Murachman, B. "On the use of sodium lignosulphonate for enhanced oil recovery", IOP Conference Series: Earth and Environmental Science, 65(1), Article number: 012030, 2017.

https://doi.org/10.1088/1755-1315/65/1/012030

[15] Ma'ruf, A., Pramudono, B., Aryanti, N. "Synthesis of Natural Surfactant of Sodium Lignosulfonate from Rice Husk Lignin by Ultrasound Assisted - Sulfonation", Key Engineering Materials, 775 , pp. $20-25,2018$.

https://doi.org/10.4028/www.scientific.net/KEM.775.20

[16] Priyanto, S., Pramudono, B., Kusworo, T. D., Suherman, Aji, H. A., Untoro, E., Ratu, P. "Synthesis Study of Surfactants Sodium Ligno Sulphonate (SLS) from Biomass Waste Using Fourier Transform Infra Red (FTIR)", MATEC Web of Conferences, 156, Article number: $03030,2018$.

https://doi.org/10.1051/matecconf/201815603030

[17] Sudrajat, R. W., Kasmiyatun, M., Suherman, S., Pramudono, B., Purba, D. A., Harlika, F. K. A. "Synthesis and characterization of sodium lignosulfonate surfactant with polyethylene glycol for enhanced oil recovery", In Proceedings of 2nd International Conference on Chemical Process and Product Engineering (ICCPPE), Semarang, Indonesia, Article number: 080001, 2020. https://doi.org/10.1063/1.5140941

[18] Qiu, X., Kong, Q., Zhou, M., Yang, D. "Aggregation Behavior of Sodium Lignosulfonate in Water Solution", The Journal of Physical Chemistry B, 114(48), pp. 15857-15861, 2010. https://doi.org/10.1021/jp107036m

[19] Teng, X., Xu, H., Song, W., Shi, J., Xin, J., Hiscox, W. C., Zhang, J. "Preparation and Properties of Hydrogels Based on PEGylated Lignosulfonate Amine", ACS Omega, 2(1), pp. 251-259, 2017. https://doi.org/10.1021/acsomega.6b00296
[20] Priyanto, S., Salsabila, F. F., Pusakawati, R., Kusworo, T. D., Pramudono, B., Untoro, E., Ratu, P. "Hydrodynamic study: The best injection pressure in enhanced oil recovery (EOR) using surfactant sodium ligno sulfonate (SLS) from black liquor", In: Proceedings of 2nd International Conference On Chemical Process And Product Engineering (ICCPPE), Semarang, Indonesia, Article number: 080005, 2020.

https://doi.org/10.1063/1.5140945

[21] Nandiyanto, A. B. D., Oktiani, R., Ragadhita, R. "How to Read and Interpret Ftir Spectroscope of Organic Material", Indonesian Journal of Science \& Technology, 4(1), pp. 97-118, 2019.

https://doi.org/10.17509/ijost.v4i1.15806

[22] Caccamo, M. T., Magazù, S. "Ethylene Glycol - Polyethylene Glycol (EG-PEG) Mixtures: Infrared Spectra Wavelet Cross-Correlation Analysis", Applied Spectroscopy, 71(3), pp. 401-409, 2017. https://doi.org/10.1177/0003702816662882

[23] Kubo, S., Kadla, J. F. "Kraft lignin/poly(ethylene oxide) blends: Effect of lignin structure on miscibility and hydrogen bonding", Journal of Applied Polymer Science, 98(3), pp. 1437-1444, 2005. https://doi.org/10.1002/app.22245

[24] Coates, J. "Interpretation of Infrared Spectra, A Practical Approach", In: Encyclopedia of Analytical Chemistry, John Wiley \& Sons Ltd., Chichester, UK, 2006, pp. 1-23. https://doi.org/10.1002/9780470027318.a5606

[25] Fu, X., Kong, W., Zhang, Y., Jiang, L., Wang, J., Lei, J. "Novel solid-solid phase change materials with biodegradable trihydroxy surfactants for thermal energy storage", RSC Advances, 5(84), pp. 68881-68889, 2015.

https://doi.org/10.1039/c5ra11842e

[26] Shao, Y., Guizani, C., Grosseau, P., Chaussy, D., Beneventi, D. "Thermal characterization and kinetic analysis of microfibrillated cellulose/lignosulfonate blends", Journal of Analytical and Applied Pyrolysis, 124, pp. 25-34, 2017. https://doi.org/10.1016/j.jaap.2017.03.001

[27] Anas, A. K., Prakoso, N. I., Sasvita, D. "The Initial Comparison Study of Sodium Lignosulfonate, Sodium Dodecyl Benzene Sulfonate, and Sodium p-Toluene Sulfonate Surfactant for Enhanced Oil Recovery", In: The 12th Joint Conference on Chemistry, Semarang, Indonesia, 2017, Article number: 012005, 2018. https://oi.org/10.1088/1757-899X/349/1/012005

[28] Lim, Z. Q., Aziz, N. A. A., Idris, A. K., Md Akhir, N. A. "Green Lignosulphonate as co-surfactant for wettability alteration", Petroleum Research, 5(2), pp. 154-163, 2020. https://doi.org/10.1016/j.ptlrs.2019.12.002

[29] Nakama, Y. "Surfactants", In: Sakamoto K., Lochead, H., Maibach, H., Yamashita, Y. (eds.) Cosmetic Science and Technology: Theoretical Principles and Applications, Elsevier, New York, USA, 2017, pp. 231-244. https://doi.org/10.1016/B978-0-12-802005-0.00015-X

[30] Pramudono, B., Aji, H. A., Priyanto, S., Kusworo, T. D., Suherman, S., Untoro, E., Ratu, P. "Utilization of Biomass Waste of Pulp and Paper Industry for Production of Sodium Lignosulphonate (SLS)", Nature Environment and Pollution Technology, 17(4), pp. 1299-1303, 2018. 
[31] Yanti, W., Kasmungin, S., Adawiyah, R., Kolanus, B. "Laboratory study of salinity and surfactant concentration effects on oil recovery", MATEC Web of Conferences, 101(5), Article number: 02008, 2017.

https://doi.org/10.1051/matecconf/201710102008

[32] Lee, K. S., Lee, J. H. "Hybrid Chemical EOR Using Low-Salinity and Smart Waterflood", In: Hybrid Enhanced Oil Recovery using Smart Waterflooding, Gulf Publishing Company, Housten, TX, USA, 2019, pp. 65-110.

https://doi.org/10.1016/B978-0-12-816776-2.00004-0

[33] Alli, Y. F., Brioletty, L., Eni, H., Irawan, Y. "Co-Surfactant Polyethylene Glycol Mono-Oleate in the Formulation of Natural Based-Surfactant for Chemical EOR", Scientific Contributions Oil and Gas, 40(1), pp. 1-8, 2017.
[34] Setiati, R., Siregar, S., Marhaendrajana, T., Wahyuningrum, D. "Surfactant Flooding for EOR Using Sodium Lignosulfonate Synthesized from Bagasse", In: Samsuri, A. (ed.) Enhanced Oil Recovery Processes - New Technologies, IntechOpen, London, UK, 2019.

https://doi.org/10.5772/intechopen.88689

[35] Zhang, G., Yu, J. "Effect of commonly used EOR polymers on low concentration surfactant phase behaviors", Fuel, 286(2), Article number: 119465, 2021.

https://doi.org/10.1016/j.fuel.2020.119465

[36] Sheng, J. J. "Status of surfactant EOR technology", Petroleum, 1(2), pp. 97-105, 2015.

https://doi.org/10.1016/j.petlm.2015.07.003 